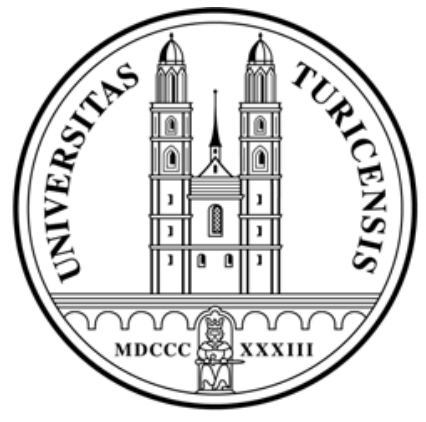

Institute for Empirical Research in Economics

University of Zurich

Working Paper Series

ISSN 1424-0459

Working Paper No. 421

Elections and Deceptions:

An Experimental Study on the Behavioral Effects of Democracy

Luca Corazzini, Sebastian Kube, Michel André Maréchal and

Antonio Nicolò

Revised version, August 2013 


\title{
Elections and Deceptions: An Experimental Study on the Behavioral Effects of Democracy*
}

\author{
Luca Corazzini, Sebastian Kube, Michel André Maréchal, and Antonio Nicolò
}

August, 2013

\begin{abstract}
Traditionally, the virtue of democratic elections has been seen in their role as means of screening and sanctioning shirking public officials. This paper proposes a novel rationale for elections and political campaigns considering that candidates incur psychological costs of lying, in particular from breaking campaign promises. These non-pecuniary costs imply that campaigns influence subsequent behavior, even in the absence of reputational or image concerns. Our lab experiments reveal that promises are more than cheap talk. They influence the behavior of both voters and their representatives. We observe that the electorate is better off when their leaders are elected democratically rather than being appointed exogenously - but only in the presence of electoral campaigns. In addition, we find that representatives are more likely to serve the public interest when their approval rates are high. Altogether, our results suggest that elections and campaigns confer important benefits beyond their screening and sanctioning functions.
\end{abstract}

JEL classification: D72, C92, D03.

Keywords: Costs of Lying, Electoral Competition, Laboratory Experiment.

\footnotetext{
* Corazzini: Department of Economics and Management "Marco Fanno", University of Padua, via del Santo, 33, 35123, Padova, Italy, email: luca.corazzini@unipd.it. Kube: University of Bonn, Department of Economics, Adenauerallee 24-42, 53113 Bonn, Germany, email: kube(at)uni-bonn.de. Maréchal: University of Zurich, Department of Economics, Laboratory for Social and Neural Systems Research, Bluemlisalpstrasse 10, CH-8006 Zurich, Switzerland, email: michel.marechal(at)econ.uzh.ch. Nicolò: Department of Economics and Management "Marco Fanno", University of Padua, via del Santo, 33, 35123, Padova, Italy, email: antonio.nicolo(at)unipd.it. Authors' names are deliberately alphabetical. The authors are grateful to Michele Bernasconi, Monika Bütler, Alain Cohn Simon Evenett, Ernst Fehr, Simon Gächter, Jens Grosser, Sally Gschwend, John Hey, Martin Leroch, Hervè Moulin, Ryan McKay, Clemens Puppe, Rupert Sausgruber, Robert Sugden, Christian Thöni, Jean-Robert Tyran, Roberto Weber as well as the audiences at the NYU Experimental Political Science Conference 2010, ASSET Meeting 2009, ESA European Regional Meeting 2008/2009, APET Conference 2009, EPCS Conference 2008, Bocconi University, Florida State University, IMT - Lucca, University of Messina, Universitat Jaume I of Castellòn, and University of Zürich for very helpful discussions and comments.
} 
"We have won with an ample margin. But, far from putting us in a position of privilege,

this puts us instead in a position of greater responsibility and obligation."

Argentina's first lady, Cristina Fernandez de Kirchner, after winning the general election with $45 \%$ of all votes - almost twice the number of the runner-up (2007/10/29)

Expenditures for political campaigns are skyrocketing (e.g. see, Benoit and Marsh 2008; Stratmann 2005) and often described as an inefficient "arms-race" (e.g. see, Abrams and Settle 2004). Although electoral campaigns are anything but cheap, rational choice scholars generally consider their content as cheap talk (e.g. see, Austen-Smith and Banks 1989; Barro 1973; Ferejohn 1986). Candidates can promise almost anything in pre-election campaigns, but voters do not have any direct means to enforce promises (see Manin, Przeworski and Stokes 1999). ${ }^{1}$

We outline a psychological rationale why voters might nevertheless benefit from elections and electoral campaigns. Our idea is based on the observation that human behavior is not characterized by pure self-interest, but is also driven by other-regarding preferences and intrinsic norm compliance (e.g. Cooper and Kagel 2009; Fehr and Schmidt 2002; Fowler and Kam 2007). Extensive experimental evidence suggests that people tend to tell the truth in strategic situations, even if reputation is not at stake (e.g., Lundquist et al. 2009). Scholars usually explain this phenomenon by arguing that people incur psychological costs if they do not live up to their promises (e.g., Gneezy 2005; Hao and Houser 2010; Shalvi et al. 2011). Several reasons for such non-pecuniary costs of lying have been suggested, as for example the desire to maintain a positive self-image (see Fischbacher and Heusi 2008; Mazar, Amir and Ariely 2008). Others have argued that individuals feel guilty if they do not meet others' expectations (see Baumeister, Stillwell and Heatherton 1994; Charness and Dufwenberg 2006). Whatever the exact roots of the costs of lying are, their existence implies that electoral campaigns might not just be cheap talk. They potentially guide future office behavior. To the extent to which promises influence the winner's subsequent behavior, the constituency might benefit from electoral competition, where candidates outrun each other with campaign promises. $^{2}$

We test our conjecture with incentivized lab experiments studying both the behavior of

\footnotetext{
${ }^{1}$ Elections serve as an indirect instrument for promoting representation. In repeated elections with nonbinding or a complete lack of term limits, voters can threaten to vote dishonest politicians out of office (e.g. see, Ferejohn 1986; Key 1966).

${ }^{2}$ More intensive campaigns are not always more beneficial for voters. For example in an environment with informational asymmetries and pandering candidates, campaigns might include socially inefficient promises. Keeping such exaggerated promises could thus imply a waste of public money.
} 
representative and voters in a stylized delegated democracy. In our benchmark "Election" treatment two candidates competed for office in an election with five voters. Both candidates simultaneously promised how much money they would distribute to the electorate if they won. Promises were not enforceable and thus non-binding for the candidates. The electorate was therefore uncertain about how their representatives would behave once elected. The winner was determined by majority rule and was entrusted with a budget that she could share with the electorate or keep for herself. This game captures the elementary tradeoff representatives face in situations where their personal interests do not coincide with those of the public.

We compare treatment Election with two additional treatments. In treatment "Random", we eliminated electoral competition by replacing the election with a random selection mechanism. The approval rate was randomly determined by the experimenter using a large die in front of all participants. By contrasting treatment Election with Random, we are able to analyze the causal effects of electoral competition on promises and office behavior. In the second additional treatment "NoCampaign", voters could choose their preferred candidate as in treatment Election, but the candidates were not allowed to run electoral campaigns. This treatment sheds light on the impact of campaign promises on the candidates' benevolence.

Our experiment provides the following insights. First, electoral competition intensified campaign promises. Candidates promised significantly more benefits in democratic elections than if they were randomly appointed. Second, promises affected subsequent office behavior. We find an average degree of promise fulfillment of roughly 60 percent, despite conflicting self-interest and the absence of reputational concerns. This suggests that lying creates nonpecuniary or psychological costs. Third, eliminating electoral competition led to a substantial drop in the candidates' benevolence. Furthermore, we observe that when candidates were not allowed to make any promises (in treatment NoCampaign), voters were just as badly off as in the absence of elections. Together, these results suggest that not only electoral competition matters, but also the ability to make pre-election promises. Finally, we found that candidates' benevolence increased with their approval rate. This indicates that costs of lying increase with the share of supporters a candidate would let down. This relationship was much weaker in the two control treatments NoCampaign and Random, where the approval rate was less or not informative about voters' expectations.

We opted for an experimental approach because it allows us to identify the impact of lying 
aversion under tightly controlled conditions. A separation of intrinsically motivated honesty from reputational motives is inherently difficult with observational field data, as politicians often face looming re-elections, future career plans, or other image concerns. Moreover, voters can weed out dishonest candidates in repeated elections, creating additional potential for selection bias. It is important to disentangle the psychological costs of lying from reputational motives and adverse selection because it improves our knowledge about how elections influence leadership behavior and it provides valuable input for the design of political institutions. We designed our experiment in such a way that we can sidestep reputational concerns and selection effects. Because our election was only for one term, voters could not punish or weed out less benevolent leaders. Moreover, all participants interacted anonymously with each other using a computer interface and their true identities were never revealed to the other participants at any point in time. Another advantage of our experimental approach is that we can exogenously assign constituencies to different democratic institutions. We thus avoid the methodological problems implied by the potential endogeneity of political institutions (e.g. see Besley and Case 2003)..$^{3}$

\section{Related Literature}

The theoretical literature has predominantly focused on two key mechanisms through which elections influence policy making. According to the accountability or moral hazard view (see Barro 1973; Ferejohn 1986; Key 1966), the threat of looming re-elections disciplines incumbents. Other theories have emphasized the role of elections as a selection device, giving voters the opportunity to weed out incompetent or dishonest politicians (see Ashworth 2005; Ashworth and de Mesquita 2008; Besley 2005; Fearon 1999; Gordon, Huber and Landa 2007). ${ }^{4}$ Disentangling selection from accountability effects is challenging, because both mechanisms often have observationally equivalent implications. A common empirical approach is to take advantage of binding term limits and to analyze how the lack of electoral incentives affects policy making in the last term. The evidence is consistent with both accountability and selection effects (see Besley and Case 2003). Alt, de Mesquita and Rose (2011) for example use variation

\footnotetext{
${ }^{3}$ We discuss potential limitations of our lab experimental approach in the conclusion.

${ }^{4}$ In the presence of informational asymmetries repeated elections can also create counterproductive incentives for politicians to pander to public opinion (see Canes-Wrone, Herron and Shotts 2001; Maskin and Tirole 2004). Woon (2012) however finds no evidence for pandering in his experimental study.
} 
in U.S. gubernatorial term limits across states and time and find that the impact of re-election incentives and selection on government performance are of similar magnitude (see also Ferraz and Finan 2011; Gagliarducci and Nannicini N.d.; Rothenberg and Sanders 2000 for further recent evidence on selection and accountability effects). We rule out reputational concerns in our study by design, and are able to control for selection effects. We therefore contribute to this extensive literature by providing novel evidence that elections convey motivational benefits beyond their mere role as selection and sanctioning devices. ${ }^{5}$

Our paper further adds to the literature in the following ways. First, scholars of pledge fulfillment analyzed the extent to which elected representatives and political parties live up to their campaign promises. Pétry (2009) surveyed 18 studies from various countries and found that 67 percent of promises are kept on average. The degree of pledge fulfillment is often noted as surprisingly high, because the general population tends to believe that politicians are untrustworthy (see Thomson 2011). While most of the literature has focused on party promises, fewer papers studied promise keeping (or congruence with pre-election issue positions) on the level of a single representative. Individual level studies have drawn similar conclusions (e.g. see Fishel 1985; Ringquist and Dasse 2004; Schwarz, Schädel and Ladner 2010; Sulkin and Swigger 2008; Sulkin 2009). Both reputational concerns and the psychological costs of lying can explain promise keeping in all existing studies. Our controlled lab experiment allows us to disentangle the psychological cost of lying from other pecuniary costs implied by a loss of reputation. Moreover, we exogenously manipulate key features of democratic institutions. We are thus able to study the causal effects of democratic institutions on candidates' behavior, complementing the existing field studies.

Second, random appointment of public officials by lot (also known as "sortition") was a core feature in the ancient Athenian democracy (see Headlam 1933; Manin, Przeworski and Stokes 1999). Various forms of sortition were also practiced in medieval and renaissance Italian city-states (mostly Florence and Venice), 16th century England, as well as in some of the Landsgemeinden in Switzerland until 1837 (see Carson and Martin 1999; Engelstad 1989; Tridimas 2011). ${ }^{6}$ A well known modern form of random selection of social decision makers are juries in court cases. Rotation schemes, as they are used for example for selecting the Presidency of the

\footnotetext{
${ }^{5}$ While our results are not confounded by selection effects, the presence of lying aversion enables elections to be used as selection devices even when campaigns would otherwise be meaningless.

${ }^{6}$ See also Elster (1989) for a more general discussion of randomization in social decision-making.
} 
Council of the European Union, also share basic features of sortition. Advocates of sortition have argued that random appointment of public officials achieves a more accurate descriptive representation (e.g. Burnheim 1985; Mueller, Tollison and Thomas 1972). Moreover, random appointment is thought to attenuate the incentives for self-interested rent-seeking activities and promotes political equality (see Lockard 2003; Mulgan 1984). Our results suggest that these potential benefits should be carefully weighed against the potential costs of less motivated representatives.

Third, several models in political economy assume, either implicitly or explicitly, that politicians' promises are credible and binding. For example, in Groseclose and Snyder (1996) candidates make binding promises that advantage specific sub-groups of voters. ${ }^{7}$ Other models show that the credibility of political campaigns depends on the repeated nature of electoral competitions (e.g., Alesina 1988, Alesina and Spear 1988). Our findings provide a behavioral rationale why winning candidates might stick to their promise even in the absence of repetitions and reputation. While we believe that reputational concerns can influence the credibility of campaigns too, our results show that reputational concerns are no necessary prerequisite.

Fourth, we add to the growing field of experimental political economy (e.g. see Grosser and Schram 2006, 2010; Kube and Puppe 2009; Morton and Williams 2010; Woon 2012). Three related studies analyzed the effects of democratic choice on cooperation and public goods provision. Hamman, Weber and Woon (2011) find higher public goods provision when contribution decisions are democratically delegated rather than decentralized. Hamman et al. complement our results by focusing on the role of elections in selecting pro-social representatives. The experiments by Dal Bó, Foster and Putterman (2010) suggest that the impact of a given rule depends on whether it was democratically chosen or exogenously imposed on the subjects through another mechanism. Olken (2010) conducted a field experiment in Indonesia to study the causal effects of direct democratic participation in local development programs. He found that direct participation in the political decision making process increased satisfaction and the perceived legitimacy of the program. We complement these studies by showing that democratic elections and higher electoral support can increase the leaders' benevolence.

Finally, a recent strand of experiments analyzed the behavioral implications of leadership

\footnotetext{
${ }^{7}$ Under this assumption, Groseclose and Snyder (1996) show that politicians do not need to target all voters with their promises, but instead target only a minimum winning coalition of voters in order to succeed in the electoral competition.
} 
(e.g. De Cremer and van Knippenberg 2005; Gächter et al. N.d.; Glöckner et al. 2011; Güth et al. 2007; Hermalin 1998). Leadership in existing experiments is typically assigned exogenously (i.e. randomly). Our results suggest that leaders may behave differently if they have to compete for leadership rather than if their role is exogenously assigned (see also Brandts, Güth and Stiehler 2006; Brandts, Cooper and Weber 2011), particularly when competition promotes promise making.

\section{Experimental Design}

We conducted laboratory experiments to study democratic elections under controlled conditions. The experiments were conducted at the University of Bonn (BonnEconLab). Subjects were randomly recruited from the BonnEconLab general subject pool, which consisted of approximately 3000 students from all disciplines (excluding psychology) and from various stages in their studies (background statistics are reported in the supporting information). We ran five sessions with a total of 210 subjects. This resulted in 10 independent constituencies for each of the three treatments. Each constituency consisted of seven participants who were randomly assigned to one of two roles: candidate (two subjects) or voter (five subjects).

Subjects made their decisions on the computer screen using the z-tree interface (Fischbacher 2007). Every computer was located in a private booth ensuring that the participants interacted anonymously with each other. This high degree of anonymity was required in order to rule out any reputational concerns among the participants. At the beginning of the experiment, all subjects received written and verbal instructions explaining the different stages of the game and the payoffs (see the Supporting Information for sample instructions). After participants had read the instructions, they answered control questions, ensuring that everyone understood the game. All earnings were computed in tokens and converted into cash using an exchange rate of $€ 4$ per 100 tokens at the end of the experiment. Subjects received an additional show-up-fee of $€ 4$ for their participation. The entire experiment lasted approximately 40 minutes.

The benchmark treatment "Election" consisted of the following five stages:

Stage 1 Campaigns: In the first stage, candidates pursued their electoral campaigns. Campaigns were non-binding and consisted of two parts. In the compulsory part, candidates promised citizens how many tokens (between 0 and the maximum budget of 450 tokens) they 
would distribute equally among the citizens. In addition, candidates had the option of sending a text message (up to 300 characters) to the electorate. Both candidates pursued their campaigns simultaneously and their campaigns were not revealed to the opponent.

Stage 2 Voting: Each citizen voted for one of the two candidates in the second stage. The winner was determined by majority rule, received a fixed payment of 30 tokens, and was entrusted with a discretionary budget of 450 tokens. The outcome of the election was only announced later on, in Stage 5 of the game.

Stage 3 Distribution: Before the candidates knew the outcome of the election, each candidate decided how many tokens she would actually distribute, conditional on winning the election with 60,80 , and 100 percent of votes. ${ }^{8}$ This design feature made it possible to analyze the behavior of both winners and losers, therefore circumventing a potential selection bias from citizens electing the more benevolent candidates.

Stage 4 Belief elicitation: In stage four, citizens had to guess how many tokens each candidate would distribute, and each candidate guessed (conditional on the outcome of the election) the average amount citizens expect her to distribute. In order to elicit beliefs in an incentive-compatible way, we rewarded correct beliefs with 10 tokens. The reward was reduced by one token for each unit that the stated belief differed from the actual value, down to a minimum of zero tokens. ${ }^{9}$

Stage 5 Payoff realization: The winner of the election was announced in the final stage and, depending on the actual approval rate and the choices made in stage 3 , the payoffs were realized.

All participants were informed that this election game was played for one round only, and that their identities were not revealed at any point in time. This allowed us to rule out reputational concerns and to test whether elections confer benefits beyond their functions as sanctioning and selection devices in repeated settings.

We conducted two additional treatments (Table 1 summarizes the tasks involved in our treatments). Treatment "Random" was identical to treatment Election, except that the electoral outcome was randomly determined by the experimenter using a large die visible for

\footnotetext{
${ }^{8}$ This approach of eliciting conditional responses is frequently used in the experimental literature and is called the "strategy method" (see Selten 1967 and Brandts and Charness 2011). At the end of the results section we show that our main results are robust if we elicit direct (i.e. unconditional) responses.

${ }^{9}$ We report our analysis of second-order beliefs in the Supporting Information.
} 
Table 1: Treatment Summary

\begin{tabular}{llll}
\hline & Election & Random & NoCampaign \\
\hline Campaign stage & Yes & Yes & No \\
Voting stage & Voters & Random device & Voters \\
Distribution stage & Yes & Yes & Yes \\
\hline
\end{tabular}

everyone. This was common knowledge among all participants. ${ }^{10}$ The campaign stage remained. This procedure eliminated electoral competition and the rationale for making generous promises. Moreover, it provides a baseline measure of candidates' benevolence in the absence of competitive pressure. In the second treatment, "NoCampaign", citizens voted for their candidates as in treatment Election, but candidates were not allowed to run electoral campaigns. By comparing NoCampaign with Election, we are able to identify the causal role of campaign promises, holding electoral competition constant. Together, our three treatments allow us to identify the causal effect of candidates' promises and electoral competition on the representatives' behavior. ${ }^{11}$

\section{Framework and Hypotheses}

In this section, we provide a simple formal framework of electoral competition and campaign promises, where voters are uninformed about the candidates' honesty. Recent theoretical approaches, analyzing the influence of costs of lying in models of spatial electoral competition, inspired our analysis (Banks 1990; Callander and Wilkie 2007; Callander 2008; Kartik and McAfee 2007). Our framework departs from these models in two dimensions. First, we assume that costs of lying increase with the rate of approval. The rationale behind this assumption is that approval rates reflect voters' expectations. As highlighted in our opening quote by Cristina Fernandez de Kirchner, voters' expectations can increase feelings of obligation and guilt in elected representatives (see also Baumeister, Stillwell and Heatherton 1994; Charness and Dufwenberg 2006 for a discussion about the relationship between feelings of guilt and ex-

\footnotetext{
${ }^{10}$ The rules of the game were transparent to all participants, and the experiment did not involve any form of deception.

${ }^{11}$ We ran an additional classroom experiment to classify the text messages candidates sent in treatments Election and Random, following Houser and Xiao (2011). Our results remain unchanged if we control for the type of text messages candidates sent. Text messages are unrelated to candidates' benevolence. However, messages that include a statement of intent or promise increase voters' expectations about what a candidate is going to distribute (and consequently increase electoral success). See the Supporting Information for more details.
} 
pectation). Second, rather than assuming that the preferences of candidates and voters are distributed over a policy space, we model a situation in which the interests of politicians and voters are unambiguously in conflict.

Following our experimental design, we assume that two candidates $i$ (where $i=A, B$ ), compete for office in a one-shot election with an odd, finite number of voters, $n \geq 3 .{ }^{12}$ Both candidates simultaneously make their promises, $P_{i}$, in the first stage of the game. Voters then cast their vote for their preferred candidate. Let us indicate the number of votes for the winner with $k$ and the simple majority with $m=\frac{n+1}{2}$. Conditional on the realized approval rate, $\frac{k}{n} \geq \frac{m}{n}=\frac{n+1}{2 n}$, the elected candidate chooses how much money $S_{i}$ she actually distributes in total to the voters. We restrict $P_{i}$ and $S_{i}$ such that they can take on any value between 0 and a discretionary budget, $I \in \mathbb{R}_{+}$, assigned to the elected candidate. We normalize the utility of the losing candidate to zero in order to simplify the analysis. The utility of the winning candidate $i$ is given by

$$
U_{i}\left(P_{i}, S_{i}, \frac{k}{n}, \beta_{i}\right)=E+I-S_{i}-\beta_{i} C_{i}\left(P_{i}, S_{i}, \frac{k}{n}\right)
$$

where $E \geq 0$ is a fixed payment or wage that cannot be distributed to the voters and $C_{i}\left(P_{i}, S_{i}, \frac{k}{n}\right)$ are the psychological costs of lying. In particular, we assume that

$$
C_{i}\left(P_{i}, S_{i}, \frac{k}{n}\right)=\left\{\begin{array}{c}
\frac{k}{n} \frac{1}{2}{\frac{\left(P_{i}-S_{i}\right)}{P_{i}}}^{2}, \text { if } P_{i}>0 \text { and } S_{i}<P_{i} \\
0, \text { otherwise. }
\end{array}\right.
$$

$\beta_{i} \geq 0$ is a parameter that captures how sensitive candidate $i$ is to the psychological costs of lying. If $\beta_{i}=0$, then lying is costless for candidate $i$. On the other hand, if $\beta_{i}>0$, then candidate $i$ is lying averse. Her utility decreases with the squared difference between her promise and the distributed amount. ${ }^{13}$ Moreover, costs of lying increase with the candidate's approval rate, $\frac{k}{n}$, and promise, $P_{i}$.

Candidates may be of two types, $H$ and $L$, differing with respect to $\beta_{i}$. In particular, let $\beta^{H}>\beta^{L}>1$ be the degree of lying-aversion for type $H$ and $L$, respectively. $\beta^{L}>1$ implies that both types of candidates distribute a positive amount when (i) they promise a strictly positive

\footnotetext{
${ }^{12}$ We refer to male voters and female candidates.

${ }^{13}$ Consonant empirical evidence for this assumption can be found in Lundquist et al. (2009). In their experiment subjects were less likely to send insincere messages in strategic situations the further their lie would deviate from the truth, in particular when the message is explicitly framed as a promise.
} 
amount and (ii) they are elected unanimously. The candidates' types are randomly drawn by nature from the same ex-ante probability distribution. In particular, let $\phi$ and $(1-\phi)$ be the probabilities that $i$ is of type $L$, respectively of type $H$. We assume that voters are uninformed about the candidates' type.

Voting is costless and compulsory. Each voter casts his vote for the candidate he expects to be the most benevolent. The ex-post utility of each voter therefore consists of any affine transformation of the amount of money the electorate receives from the elected representative.

Focusing on Perfect Bayesian equilibria where voters do not play weakly dominated strategies $^{14}$, the model yields the following testable predictions:

H1. Candidates promise to be more benevolent when they face electoral competition than when they are randomly appointed.

H2. The candidates' promises influence voting behavior.

H3. Voters are better off when candidates are democratically elected and run campaigns, rather than when leaders are randomly selected or when they are not allowed to run electoral campaigns.

H4. The larger candidates' promises and the higher their approval rates, the more benevolent are the elected candidates.

The intuition behind these theoretical predictions is as follows (formal proofs and additional results are in the Supporting Information). From equation (2) we can infer that every candidate who promises zero, will distribute nothing, and every candidate who makes a positive promise, since $\beta^{L}>1$, will distribute a fraction of her promise (that is increasing with the approval rate). ${ }^{15}$ In treatment Election voters anticipate that promises are partially fulfilled and cast their vote for the candidate who promises to distribute the larger amount. Because promises are not considered as cheap talk candidates use them strategically to win the election. The electoral competition thus induces candidates to outbid each others' promises.

In treatment NoCampaign candidates cannot make any campaign promises. Similarly, the absence of electoral competition in treatment Random implies that candidates have no incentive to promise positive amounts. In both cases, winning candidates distribute nothing and suffer

\footnotetext{
${ }^{14}$ As shown in the Supporting Information, this assumption rules out unintuitive equilibria where voters prefer candidates who promise and distribute zero rather than candidates who promise and distribute strictly positive amounts.

${ }^{15}$ The model admits multiple equilibria in which the promises made by candidates are strictly lower than the budget $I$.
} 
no psychological cost because they did not promise anything in the first place. Consequently, voters receive higher payoffs when candidates compete for appointment with campaign promises rather than when they are randomly selected or in the absence of electoral campaigns.

These theoretical predictions would change if candidates did not incur psychological costs of lying. For example, when candidates are purely self-interested, the winning candidates do not distribute anything in either treatment, irrespective of their promises. Promises are therefore cheap talk and voters do not take them into account when they cast their vote. Similarly, in a model where candidates are motivated by other-regarding preferences (e.g., altruism or inequality aversion) instead of lying aversion, their benevolence would not differ across treatments. ${ }^{16}$ Pro-social candidates would, irrespective of their promises, always distribute whatever is optimal for them, given their degree of pro-sociality. ${ }^{17}$

\section{Experimental Results}

Our results are presented in three steps. First, we analyze the impact of electoral competition on campaign promises. We then test whether voters consider promises to be cheap talk, and whether electoral outcomes reflect voters' expectations. Finally, we investigate the extent to which electoral competition and campaigns affect the behavior of office holders.

\section{Campaigns}

Figure 1 shows kernel density estimates for the amount of money the candidates promised, depending on whether they were democratically elected (Election) or appointed by lot (Random).

While candidates frequently promised low amounts of money in treatment Random, most promises in treatment Election were in the top range of the available budget. In comparison with treatment Random, promises in Election were on average twice as high (165 versus 325 tokens). This difference is statistically significant according to a Wilcoxon rank-sum test ( $p=$ 0.001). ${ }^{18}$ Many candidates in treatment Election do not promise the maximum amount of distributable tokens, but their promises seem to be driven by concerns for equality. The

\footnotetext{
${ }^{16}$ Although selfish candidates would mimic pro-social competitors by making the same equilibrium promises in treatment Election.

${ }^{17}$ In the presence of other-regarding preferences, candidates' benevolence only differs between treatments when we add psychological costs of lying. In the Supporting Information we discuss how to extend our model with such a combination of other-regarding preferences and psychological costs of lying.

${ }^{18}$ All reported p-values are based on two-sided tests.
} 
Figure 1: Electoral competition and Promises

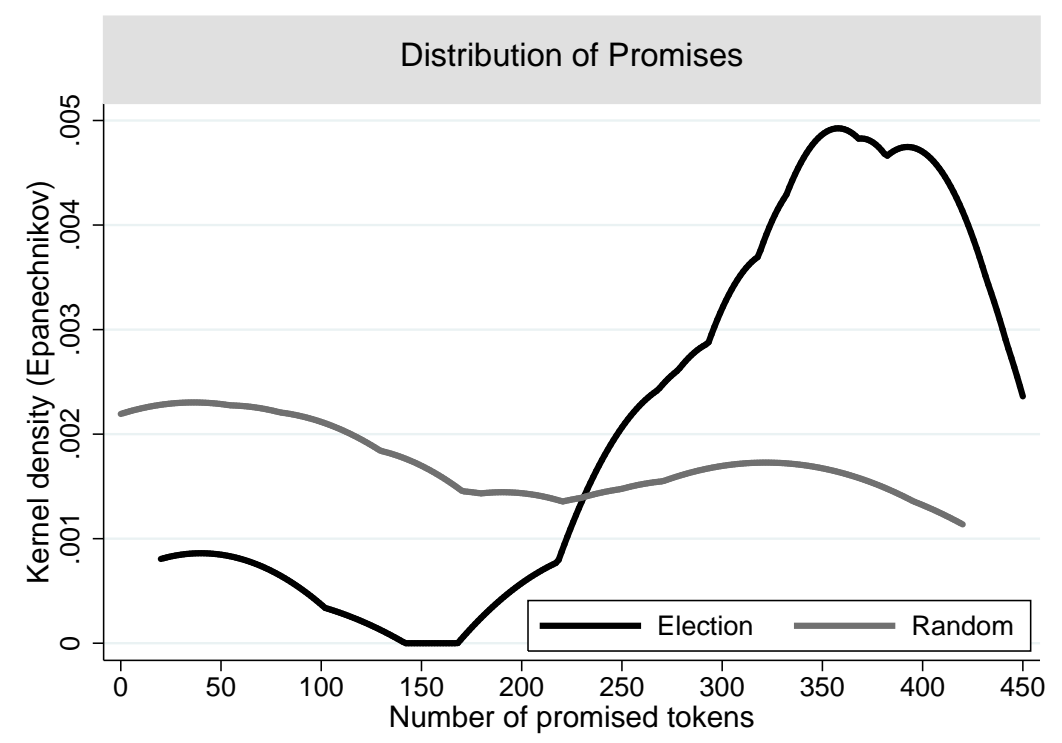

density in Figure 1 peaks at 375 and 400 tokens, which (depending on whether the winner's fixed payment of 30 is considered in the calculations) imply equal payoffs for the winner and voters. The following result summarizes our findings:

Result 1. Electoral competition triggers more generous campaign promises.

\section{Voting}

Do voters take campaign promises into account? We analyze how promises influence voters' expectations using the following regression model:

$$
E_{n c}\left[S_{i}\right]=\alpha+\beta_{1} P_{i c}+\epsilon_{n i c}
$$

Where $E_{n c}\left[S_{i}\right]$ is the average number of tokens that voter $n$ in constituency $c$ believes candidate $i$ will distribute. $P_{i c}$ is the promise candidate $i$ in constituency $c$ makes. The model is estimated using Ordinary Least Squares (OLS). Standard errors are corrected for clustering, accounting for dependency of the error term $\epsilon_{\text {nic }}$ within each constituency. ${ }^{19}$ We extend our empirical model and include $\beta_{2} P_{i c}^{2}$ in order to test whether excessively high promises are less credible.

\footnotetext{
${ }^{19}$ The results remain qualitatively the same if we use a Tobit model instead.
} 
Table 2: Promises and Expectations

\begin{tabular}{lll}
\hline & $(1)$ & $(2)$ \\
\hline Promise & $0.426^{* * *}$ & $1.174^{* * *}$ \\
& $(0.101)$ & $(0.127)$ \\
$(\text { Promise })^{2}$ & & $-0.002^{* * *}$ \\
& & $(0.000)$ \\
Constant & $89.125^{* *}$ & $30.004^{* * *}$ \\
& $(31.477)$ & $(6.258)$ \\
\hline $\mathrm{R}^{2}$ & 0.112 & 0.138 \\
Obs. & 100 & 100 \\
Sample & Election & Election \\
\hline
\end{tabular}

Notes: This table shows OLS coefficient estimates (standard errors in parentheses are corrected for clustering on the level of each electorate). The dependent variable is the number of tokens voter $n$ believed that candidate $i$ would distribute. "Promise", resp. "(Promise) ${ }^{2}$ " is the (squared) number of tokens the candidate promised. The results remain qualitatively the same if we use a Tobit model as an alternative. Significance levels are denoted as follows: ${ }^{*} \mathrm{p}<0.1,{ }^{* *} \mathrm{p}<0.05,{ }^{* * *} \mathrm{p}<0.01$.

The results from column (1) of Table 2 show that promises have a significant influence on expectations, suggesting that voters do not consider promises to be merely cheap talk. However, the significant coefficient for squared promises in column (2) suggests that the relationship between promises and beliefs is hump-shaped. ${ }^{20}$ The decrease in credibility is reasonable, given that fulfilling very generous promises is more costly for candidates. According to the regression results, promises which exceed 375.5 tokens become less credible. Strikingly, the peak mentioned above at 375 in the distribution of promises in Figure 1 suggests that candidates correctly anticipated this nonlinear relationship.

We complement these results and estimate the effect of promises on voting behavior using the following linear empirical model:

$$
v_{n A c}=\alpha+\beta_{1}\left(P_{A c}-P_{B c}\right)+\epsilon_{n A c},
$$

where $v_{n A c}$ is a dummy variable indicating whether voter $n$ in constituency $c$ supported candidate $A . P_{A c}-P_{B c}$ is the absolute difference between promises (in hundreds of tokens) between candidate A and B. We used $\mathrm{OLS}^{21}$ to estimate the linear probability model in equation 4 and corrected the standard errors for clustering of voting decisions within each constituency. We separately included the squared difference in promises $\left(\beta_{2}\left(P_{A c}-P_{B c}\right)^{2}\right)$ to capture poten-

\footnotetext{
${ }^{20}$ See the Supporting Information for a visualization of the relationship.

${ }^{21}$ The results are robust if we use a Probit model.
} 


\begin{tabular}{lll}
\hline & $(1)$ & $(2)$ \\
\hline$\Delta_{A, B}$ Promise & 0.146 & $0.321^{* * *}$ \\
$\left(\Delta_{A, B} \text { Promise }\right)^{2}$ & $(0.116)$ & $(0.088)$ \\
& & $-0.194^{* * *}$ \\
Constant & $0.579^{* * *}$ & $(0.057)$ \\
& $(0.096)$ & $0.684^{* * *}$ \\
\hline $\mathrm{R}^{2}$ & 0.065 & $(0.082)$ \\
Obs. & 50 & 0.180 \\
Sample & Election & 50 \\
\hline
\end{tabular}

Notes: This table shows OLS coefficient estimates (standard errors in parentheses are corrected for clustering on the level of each electorate). The dependent variable is a dummy variable indicating whether a voter casted his vote for candidate A. " $\Delta_{A, B}$ Promise" respectively " $\left(\Delta_{A, B}\right.$ Promise $)$ " is the (squared) difference between the number of tokens candidates $\mathrm{A}$ and $\mathrm{B}$ promise (in hundreds of tokens).The results remain qualitatively the same if we use a Probit model as an alternative. Significance levels are denoted as follows: ${ }^{*} \mathrm{p}<0.1,{ }^{* *} \mathrm{p}<0.05,{ }^{* * *} \mathrm{p}<0.01$.

tial nonlinearities. The results in column (1) of Table 3 suggest that voters tend (although not statistically significant) to vote for the candidate who promises more than his opponents. However, the results in column (2) show that the moderate effect in column (1) is masked by a statistically significant nonlinear relationship: more generous promises increase political support but only up to a certain point. Based on the parameter estimates electoral success is, ceteris paribus, maximized for promises exceeding the opponents promise by 82.7 tokens (see also the corresponding figure in the Supporting Information).

Overall, we find that the electoral outcome reflects voters' expectations about the candidates' benevolence. In nine out of ten elections, voters elected the candidate whom they expected to be more benevolent $\left(\chi^{2}\right.$-test: $\left.p=0.016\right)$. The main findings are summarized in our second result:

Result 2. Voters do not treat promises as cheap talk and take them into account when deciding whom to vote for. Election outcomes reflect voters' expectations about the candidates' benevolence.

\section{Benevolence of Representatives}

We have shown that candidates promise more if they face electoral competition rather than if they are randomly appointed. But do candidates live up to their promises? We answer 
this question by creating a measure of promise fulfillment. Our measure consists of the ratio between the actual number of distributed tokens and the candidate's promise. ${ }^{22}$ On average, we find relatively high levels of pledge fulfillment in treatment Election $(59.8 \%$ with a $95 \%$ confidence interval of: $43.8 \%, 75.7 \%)$ as well as in Random $(63.4 \%$ with a $95 \%$ confidence interval of: $42.8 \%, 84.0 \%$ ). The similarity in pledge fulfillment suggests that elections do not cause differences in the degree of lying aversion but operate through candidate competition (see also the corresponding figure in the Supporting Information which depicts the distribution of pledge fulfillment ratios). Strikingly, these rates of pledge fulfillment are comparable with the degree of pledge fulfillment observed in field studies (see Pétry 2009).

Given that promises were partially fulfilled, the more generous promises in Election translated into higher monetary benefits for the voters. The cumulative distribution functions for the number of distributed tokens in Figure 2 show that voters were substantially more likely to be better off in treatment Election than in Random. For example, the probability that a candidate distributed more than a hundred tokens is 0.75 in the Election treatment, but only 0.2 in Random.

Figure 2: Democratic Institutions and Benevolence

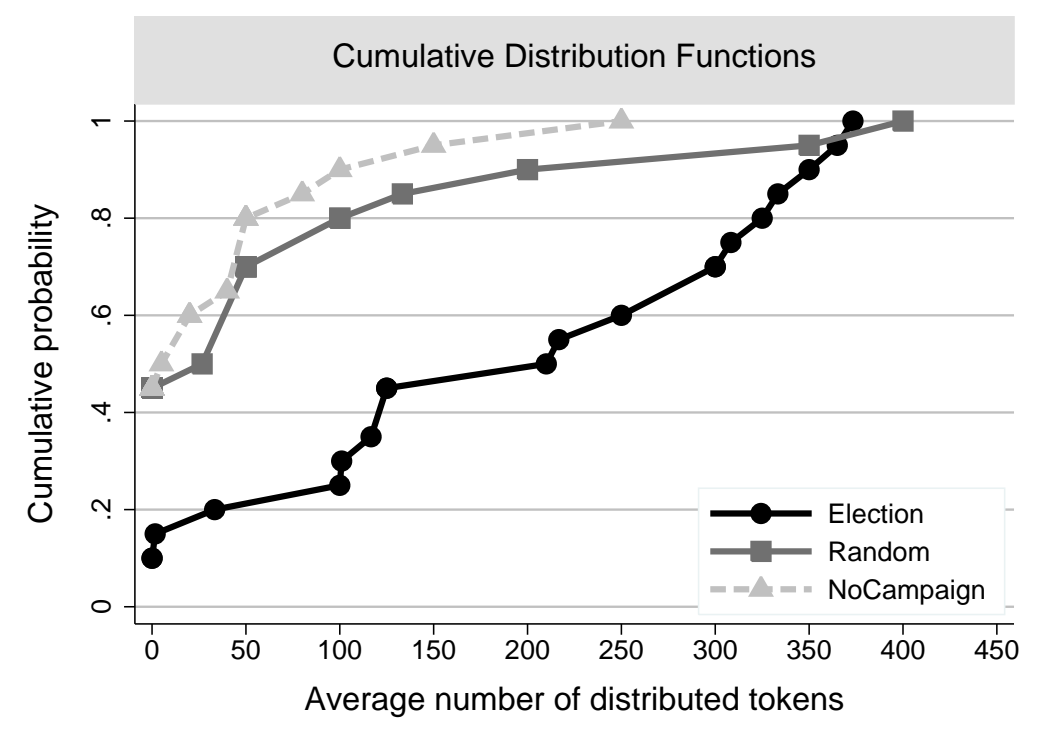

On average (over all approval rates), candidates distributed 197 tokens in treatment Elec-

\footnotetext{
${ }^{22}$ Four candidates distributed a larger amount than what they promised. We set their ratio of pledge fulfillment to 1 in our analysis.
} 
tion, but only 76 tokens in treatment Random. The difference is statistically significant $(p=0.003)$ according to a Wilcoxon rank-sum test. ${ }^{23}$

Table 4: Democratic Institutions and Benevolence

\begin{tabular}{llll}
\hline & $(1)$ & $(2)$ & $(3)$ \\
\hline Election & $121.217^{* * *}$ & 57.169 & $121.217^{* * *}$ \\
& $(39.392)$ & $(49.205)$ & $(39.392)$ \\
Promise & & $0.401^{* * *}$ & \\
NoCampaign & & $(0.139)$ & -34.750 \\
& & & $(29.696)$ \\
Constant & & 9.448 & $75.500^{* * *}$ \\
& $\left(25.500^{* * *}\right.$ & $(14.178)$ & $(26.005)$ \\
\hline Wald test: & & & 0.000 \\
Election=NoCampaign & & & 0.287 \\
\hline $\mathrm{R}^{2}$ & 0.199 & 0.351 & 60 \\
Obs. & 40 & 40 & Full \\
Sample & Election & Election & \\
& \& Random & \& Random & \\
\hline
\end{tabular}

Notes: This table shows OLS coefficient estimates (with robust standard errors in parentheses). The dependent variable is the number of tokens (averaged over all three approval rates) that candidates distributed. "Election" and "NoCampaign" are treatment dummy variables. Random is considered as the reference category. "Promise" is the number of tokens the candidate promised. The results remain qualitatively the same if we use a Tobit model as an alternative. Significance levels are denoted as follows: ${ }^{*} \mathrm{p}<0.1,{ }^{* *} \mathrm{p}<0.05,{ }^{* * *} \mathrm{p}<0.01$.

The OLS regression results in column (1) of Table 4 corroborate the nonparametric analysis. We estimated the following linear regression model:

$$
S_{i}=\alpha+\beta_{1} E_{i}+\epsilon_{i},
$$

where $S_{i}$ is the number of tokens distributed by candidate $i$ (averaged over all three approval rates) and $E_{i}$ is a dummy for treatment Election. The results in column (1) show that candidates distribute 121 tokens more in treatment Election than in Random. In column (2), we additionally control for promises and find that they significantly predict the candidates' actual office behavior. Remarkably, the coefficient for $E_{i}$ is much smaller and is no longer statistically significant when we control for promises, suggesting that the treatment effect is mediated through promises.

\footnotetext{
${ }^{23}$ We alternatively compared the distributed amount in Election and Random for each approval rate separately and found that all the differences are statistically significant using Wilcoxon rank-sum tests $(p<0.05)$.
} 
In treatment NoCampaign, candidates could not make any pre-election promises. Comparing treatments Election and NoCampaign therefore provides more direct evidence on the influence of promises. As shown in Figure 2, candidates are much more likely to distribute lower numbers of tokens in NoCampaign than in Election. On average, candidates distributed only 41 tokens in NoCampaign. This is significantly less than in treatment Election (Wilcoxon rank-sum test: $p<0.001)$. Although candidates distributed slightly more tokens in Random than in NoCampaign, the difference is statistically insignificant $(p=.522)$. The regression estimates reported in column (3) of Table 4 confirm these nonparametric results. We summarize the findings as follows:

Result 3. Representatives behave more benevolently when they are democratically elected than when they are randomly appointed by lot. The difference seems to be driven by the less generous promises in the absence of electoral competition. Eliminating the possibility of making campaign promises leads to a corresponding reduction in the monetary payoff for the electorate.

We have shown that the approval rate in an election is a signal of how much voters trust the candidates. The psychological costs of disappointing others should therefore increase with the approval rate in the Election treatment. In contrast, the randomly generated approval rate in treatment Random contains no information about voters' expectations. And in the NoCampaign treatment, voters have no information about the different candidates, i.e. the voters' choices can be considered unintentional. We should consequently see a positive correlation between approval rates and the number of tokens distributed in the Election treatment, but not in treatments Random or NoCampaign. Figure 3 provides supporting evidence.

The number of tokens distributed markedly increased with the approval rate in the Election treatment, while it remained much flatter in the other two treatments, where approval rates contained less or no information.

In Table 5 , we separately regress the number of tokens distributed by candidate $i$ on the approval rates $\frac{k}{n}$ for each treatment. We further included promises $P_{i}$ as an additional explanatory variable in our linear regression model for treatment Election and Random (see equation 7). Standard errors are adjusted for clustering of the error term $\epsilon_{i}$ on the level of each candidate.

$$
S_{i}\left(\frac{k}{n}\right)=\alpha+\beta_{1}\left(\frac{k}{n}\right)+\beta_{2} P_{i}+\epsilon_{i}
$$


Figure 3: Political Support and Voter's Material Welfare

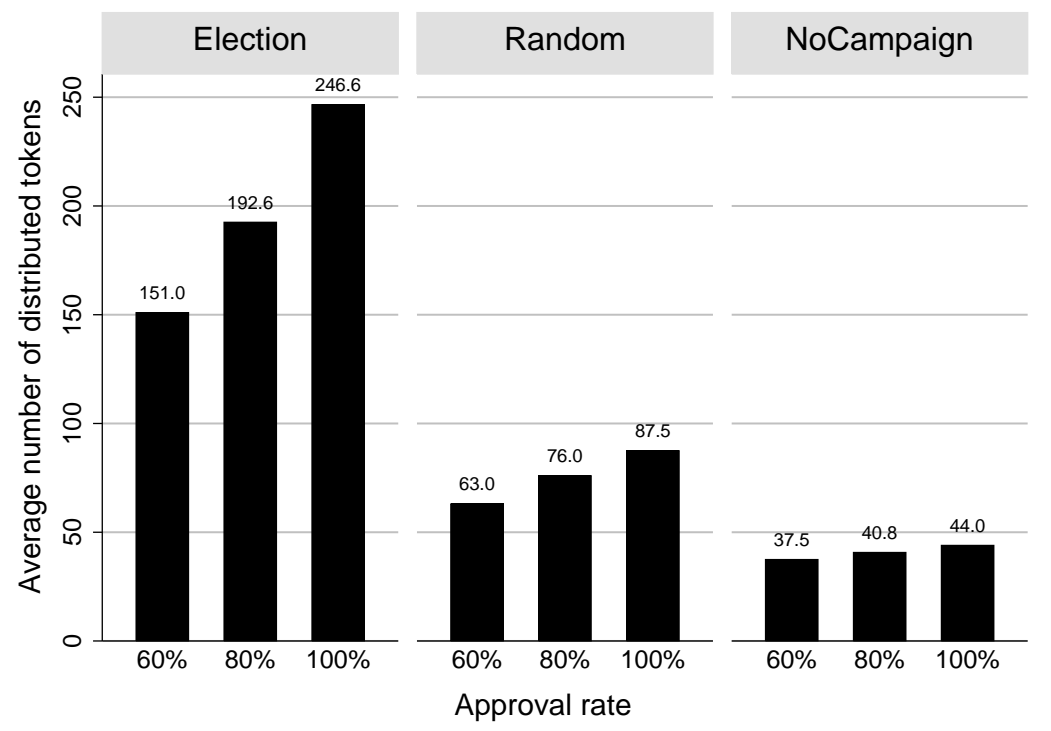

In the Election treatment (column 1), we find that the coefficient for the approval rate is positive and highly significant $(p<0.001)$. In contrast, the approval rate has a much lower impact on the candidates' behavior in Random (see column (2)). The coefficient for the approval rate is almost four times smaller than in Election and only reaches marginal significance $(p<0.1)$. We find no significant relationship between approval rates and benevolence in the NoCampaign treatment (see column (3) in Table 5). To test whether the relationship between the approval rate and the voters' payoff is significantly stronger in Election than in NoCampaign and Random, we pooled the data from all three treatments and added interaction terms between the treatment dummies and the approval rate in column (4). The interaction term for the Election treatment is large and statistically significant. A Wald tests rejects the null hypothesis that the coefficients for "Approval*Election" and "Approval*Random" are equally large $(p=0.012)$. Our last result summarizes these findings:

Result 4. The higher candidates' approval rates are, the more benevolently do they behave. This relationship is absent or much less pronounced when approval rates are based on random or uninformed voting.

By asking for a conditional distribution choice for each approval rate, we might have artificially induced candidates to condition their decisions on the approval rates. In order to rule 
Table 5: Approval Rates and Benevolence

\begin{tabular}{lllll}
\hline & $(1)$ & $(2)$ & $(3)$ & $(4)$ \\
\hline Approval (in \%) & $2.390^{* * *}$ & $0.613^{*}$ & 0.163 & $0.163^{* *}$ \\
& $(0.562)$ & $(0.325)$ & $(0.197)$ & $(0.063)$ \\
Promise & $0.427^{* * *}$ & $0.387^{*}$ & & \\
Election & $(0.138)$ & $(0.201)$ & & -22.233 \\
& & & $(52.367)$ \\
Random & & & -1.250 \\
& & & $(29.146)$ \\
Approval*Election & & & $2.227^{* * *}$ \\
& & & & $(0.602)$ \\
Approval*Random & & & & 0.450 \\
& & & & $(0.295)$ \\
Constant & $-133.088^{* *}$ & -37.233 & 27.750 & 27.750 \\
& $(60.224)$ & $(26.297)$ & $(22.631)$ & $(16.708)$ \\
\hline $\mathrm{R}^{2}$ & 0.188 & 0.258 & 0.002 & 0.296 \\
Obs. & 60 & 60 & 60 & 180 \\
Sample & Election & Random & NoCampaign & Full \\
\hline
\end{tabular}

Notes: This table shows OLS coefficient estimates (standard errors are given in parentheses and corrected for clustering on the level of each candidate). The dependent variable is the number of tokens candidates distributed to the electorate for each approval rate. The variable "Approval (in \%)" indicates the approval rate. "Election" and "Random" are dummy variables indicating the Election and the Random treatments, respectively. "NoCampaign" is considered the reference category in column (4). The results remain qualitatively the same if we use a Tobit model as an alternative. Significance levels are denoted as follows: ${ }^{*} \mathrm{p}<0.1,{ }^{* *} \mathrm{p}<0.05,{ }^{* * *} \mathrm{p}<0.01$.

out the possibility that our results are an artifact of the strategy method, we used the direct response method in the additional control treatment "Election (direct)". The winning candidate made a single distribution decision only after having learned the electoral outcome. In order to increase the number of observations we reduced the number of voters per constituency to three, and repeated the game for three periods. We excluded reputational concerns by rematching the candidates with a new set of voters and a new contestant in every period. Based on 220 recruited subjects we collected 132 distribution decisions from elected representatives (see Supporting Information for more details on the experimental design).

Figure 4 shows that we replicated our main result with the direct response method, suggesting that the relationship between approval rate and benevolence is not an artifact of the strategy method. Candidates elected with unanimity distributed $38 \%$ more money than those elected with two third's majority.

In Table 6 we used OLS to regress the number of tokens distributed by candidate $i$ in period 
Figure 4: Approval and Benevolence (Direct Response Method)

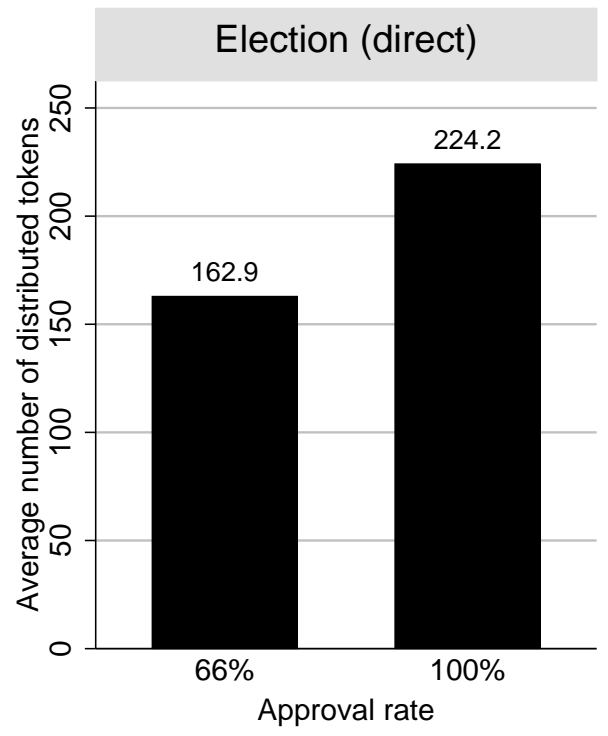

$t$ on the approval rates $\frac{k}{n}$. We control for promises $P_{i t}$ because they might have influenced the approval rates (see equation 7). Standard errors are adjusted for clustering of the error term $\epsilon_{i c t}$ on the level of each constituency.

$$
S_{i c t}=\alpha+\beta_{1}\left(\frac{k}{n}\right)+\beta_{2} P_{i t}+\epsilon_{i c t},
$$

The results in column (1) show that the relationship between approval rates and benevolence is statistically significant. Moreover, we cannot reject that the coefficient is equally large as the one found using the strategy method in column $(2)$ of Table $5(p=0.585)$. In column (2) we additionally included the control variable Experience, which indicates the number of times candidate $i$ has been elected in a specific period $t$. The coefficient estimate suggests that experience has no significant influence on representatives' benevolence.

\section{Conclusion}

This paper sheds novel light on the role of campaign promises in democratic elections using an experiment where the behavior of both representatives and voters can be studied under controlled conditions. Our findings show that electoral competition promoted candidates to make more generous campaign promises, and that promises are partially fulfilled. Voters were 
Table 6: Regression Results (Direct Response Method)

\begin{tabular}{lll}
\hline & $(1)$ & $(2)$ \\
\hline Approval (in \%) & $1.983^{* * *}$ & $1.993^{* * *}$ \\
& $(0.490)$ & $(0.489)$ \\
Promise & $0.442^{* *}$ & $0.464^{* *}$ \\
& $(0.192)$ & $(0.202)$ \\
Experience & & -11.617 \\
& & $(12.550)$ \\
Constant & -119.662 & -121.935 \\
& $(83.814)$ & $(83.455)$ \\
\hline $\mathrm{R}^{2}$ & 0.063 & 0.066 \\
Obs. & 132 & 132 \\
Sample & Election (direct) & Election (direct) \\
\hline
\end{tabular}

Notes: This table shows OLS coefficient estimates (standard errors in parentheses are corrected for clustering on the level of each session). The dependent variable is the number of tokens candidates distributed to the electorate in period $t$. The variable "Approval (in \%)" indicates the approval rate. "Experience" captures the number of times a candidate was elected and "Promise" is the number of tokens the candidate promised. Significance levels are denoted as follows: ${ }^{*} \mathrm{p}<0.1,{ }^{* *}$ $\mathrm{p}<0.05,{ }^{* * *} \mathrm{p}<0.01$

therefore better off in elections rather than if their leaders were randomly appointed - but only if candidates were given the opportunity to make campaign promises. Our analysis of voting behavior showed that voters did not consider promises as cheap talk and that they cast their votes for candidates who promised more. However, this relationship was nonlinear, as voters considered extremely generous campaign promises to be implausible.

These findings have important implications for the advancement of both theoretical work on and the design of democratic institutions. Our empirical evidence is supportive for nascent theoretical approaches considering lying aversion and character in formal models of campaign promises and policy making (see Banks 1990; Callander and Wilkie 2007; Callander 2008; Kartik and McAfee 2007). More generally, our results are informative for the design of social decisionmaking mechanisms. They suggest that exogenous rather than the democratic assignment of decision rights, as in office rotation schemes, for example, might produce unwanted side-effects due to less intrinsically motivated representatives. Non-pecuniary motivational effects provide a novel explanation for recent empirical findings showing that elected regulators or judges behave differently than appointed ones (see Besley and Case 2003).

Although our controlled experiment allows for straightforward causal interpretations, this approach also entails limitations. For example, in order to properly identify the psychological 
cost of lying, we had to impose a higher degree of anonymity than typically present in reality. How reputational concerns interact with psychological motivations is an interesting open question. Some experimental evidence suggests that reputational concerns are complementary and amplify pro-social behavior in social dilemmas (e.g. Brown, Falk and Fehr 2004). Another potential concern is that our student subject pool is not necessarily representative for professional politicians. However, the existing evidence comparing students with non-standard subject pools such as CEOs, public servants, or representative populations suggests that student samples tend to provide a lower bound for the relevance of pro-social behavior (see Alatas et al. 2009; Cappelen et al. 2011; Falk, Meier and Zehnder N.d.; Fehr and List 2004). Moreover, Dawes, Loewen and Fowler (2011) provide evidence suggesting that the relationship between social preferences and political participation is positive.

We believe that our experiment provides a simple and parsimonious framework that can be further enriched, opening interesting avenues for future research. For example, one could analyze self-selection by adding a stage where each participant is given the choice of running for office. Other extensions include allowing representatives to target their promises and benevolence to specific groups of voters such that minimum winning coalitions could potentially emerge (see Groseclose and Snyder 1996). In general, the controlled lab environment opens up many opportunities for learning more about the interplay between institutions (that differ for example in their degree of democratic legitimacy) and policymaking. 


\section{References}

Abrams, Burton A. and Russel F. Settle. 2004. "Campaign Finance Reform: A Public Choice Perspective." Public Choice 120:379-400.

Alatas, Vivi, Lisa Cameron, Ananish Chaudhuri, Nisvan Erkal and Lata Gangadharan. 2009. "Subject Pool Effects in a Corruption Experiment: A Comparison of Indonesian Public Servants and Indonesian Students." Experimental Economics 12:113-132.

Alesina, Alberto. 1988. "Credibility and Policy Convergence in a Two-Party System with Rational Voters." American Economic Review 78:796-805.

Alesina, Alberto and Stephen E. Spear. 1988. "An Overlapping Generations Model of Electoral Competition." Journal of Public Economics 37:359-379.

Alt, James, Ethan Bueno de Mesquita and Shanna Rose. 2011. "Disentangling Accountability and Competence in Elections: Evidence from U.S. Term Limits." Journal of Politics 73(1):171-186.

Ashworth, Scott. 2005. "Reputational Dynamics and Political Careers." Journal of Law, Economics, and Organization 21(2):441-466.

Ashworth, Scott and Ethan Bueno de Mesquita. 2008. "Electoral Selection, Strategic Challenger Entry, and the Incumbency Advantage." Journal of Politics 70(3):1006-1025.

Austen-Smith, David and Jeffrey Banks. 1989. Electoral Accountability and Incumbency. In Models of strategic choice in politics, ed. P.C. Ordeshook. Ann Arbor: University of Michigan Press.

Banks, Jeffrey S. 1990. "A Model of Electoral Competition with Incomplete Information." Journal of Economic Theory 50(2):209-325.

Barro, Robert J. 1973. "The Control of Politicians: An Economic Model." Public Choice $14(1): 19-42$.

Baumeister, Roy F., Arlene M. Stillwell and Todd F. Heatherton. 1994. "Guilt: An Interpersonal Approach." Psychological Bulletin 115(2):243-267. 
Benoit, Kenneth and Michael Marsh. 2008. "The Campaign Value of Incumbency: A New Solution to the Puzzle of Less Effective Incumbent Spending." American Journal of Political Science 52:874-890.

Besley, Timothy. 2005. "Political Selection." Journal of Economic Perspectives 19(3):43-60.

Besley, Timothy and Anne Case. 2003. "Political Institutions and Policy Choices: Evidence from the United States." Journal of Economic Literature 41(1):7-73.

Brandts, Jordi, David Cooper and Roberto Weber. 2011. "Legitimacy, Social Distance, and Leadership in the Turnaround Game." Working Paper Department of Economics, Florida State University .

Brandts, Jordi and Gary Charness. 2011. "The Strategy Versus the Direct-response Method: A First Survey of Experimental Comparisons." Experimental Economics 2(3):227-238.

Brandts, Jordi, Werner Güth and Andreas Stiehler. 2006. "I want YOU! An Experiment Studying Motivational Effects When Assigning Distributive Power." Labour Economics 13(1):1-17.

Brown, Martin, Armin Falk and Ernst Fehr. 2004. "Relational contracts and the nature of market interactions." Econometrica 72(3):747-780.

Burnheim, John. 1985. Is democracy possible?: The alternative to electoral politics. University of California Press.

Callander, Steven. 2008. "Political Motivations." Review of Economic Studies 75(3):671-697.

Callander, Steven and Simon Wilkie. 2007. "Lies, Damned Lies, and Political Campaigns." Games and Economic Behavior 60(2):262-286.

Canes-Wrone, Brandice, Michael C. Herron and Kenneth W. Shotts. 2001. "Leadership and pandering: A theory of executive policymaking." American Journal of Political Science $45(3): 532-550$.

Cappelen, Alexander W., Knut Nygaard, Erik Sorensen and Bertil Tungodden. 2011. "Social Preferences in the Lab: A Comparison of Students and a Representative Population." Working Paper. 
Carson, Lyn and Brian Martin. 1999. Random Selection in Politics. Westpoint, Conn. and London: Praeger.

Charness, Gary and Martin Dufwenberg. 2006. "Promises and Partnership." Econometrica 74(6):1579-1601.

Cooper, David J. and John H. Kagel. 2009. "Other Regarding Preferences: A Selective Survey of Experimental Results." Unpublished manuscript .

Dal Bó, Pedro, Andrew Foster and Louis Putterman. 2010. "Institutions and Behavior: Experimental Evidence on the Effects of Democracy." American Economic Review 100:2205-2229.

Dawes, Christopher T., Peter John Loewen and James H. Fowler. 2011. "Social Preferences and Political Participation." Journal of Politics 73:845-856.

De Cremer, David and Daan van Knippenberg. 2005. "Cooperation as a Function of Leader Self-Sacrifice, Trust, and Identification." Leadership and Organization Development Journal 26(5):355-369.

Elster, Jon. 1989. Solomonic Judgements. Cambridge: Cambridge University Press.

Engelstad, Fredrik. 1989. "The Assignment of Political Office By Lot." Social Science Information 28:23-50.

Falk, Armin, Stephan Meier and Christian Zehnder. N.d. "Do Lab Experiments Misrepresent Social Preferences? The Case of Self-selected Student Samples." Journal of the European Economic Association. Forthcoming.

Fearon, James D. 1999. Electoral Accountability and the Control of Politicians: Selecting Good Types versus Sanctioning Poor Performance. In Democracy, Accountability, and Representation, ed. Adam Manin, Bernard Przeworski and Susan Stokes. Cambridge: Cambridge University Press.

Fehr, Ernst and John A. List. 2004. "The hidden costs and returns of incentives - trust and trustworthiness among CEOs." Journal of the European Economic Association 2(5):743-771.

Fehr, Ernst and Klaus M. Schmidt. 2002. Theories of Fairness and Reciprocity - Evidence and Economic Applications. In Advances in Economics and Econometrics, 8th World Congress, 
Econometric Society Monographs, ed. L. Hansen M. Dewatripont and S. Turnovsky. Cambridge: Cambridge University Press.

Ferejohn, John. 1986. "Incumbent Performance and Electoral Control." Public Choice 50(1):526.

Ferraz, Claudio and Frederico Finan. 2011. "Electoral Accountability and Corruption: Evidence from the Audits of Local Governments." American Economic Review 101(4):1274-1311.

Fischbacher, Urs. 2007. "Z-Tree: Zurich Toolbox for Ready-Made Economic Experiments." Experimental Economics 10(2):171-178.

Fischbacher, Urs and Franziska Heusi. 2008. Lies in Disguise - An Experimental Study on Cheating. TWI Research Paper Series 40.

Fishel, Jeff. 1985. Presidents and promises: From campaign pledge to presidential performance. Washington, D.C.: CQ Press.

Fowler, James H. and Cindy D. Kam. 2007. "Beyond the Self: Social Identity, Altruism, and Political Participation." Journal of Politics 69(3):813-827.

Gächter, Simon, Daniele Nosenzo, Elke Renner and Martin Sefton. N.d. "Who Makes a Good Leader? Cooperativeness, Optimism, and Leading-by-Example." Economic Inquiry. Forthcoming.

Gagliarducci, Stefano and Tommaso Nannicini. N.d. "Do Better Paid Politicians Perform Better? Disentangling Incentives from Selection." Journal of the European Economic Association. Forthcoming.

Glöckner, Andreas, Bernd Irlenbusch, Sebastian Kube, Andreas Nicklisch and Hans-Theo Normann. 2011. "Leading with(out) Sacrifice? A Public-Goods Experiment with a SuperAdditive Player." Economic Inquiry 49(2):591-597.

Gneezy, Uri. 2005. "Deception: The role of consequences." American Economic Review 95:384394.

Gordon, Sanford C., Gregory A. Huber and Dimitri Landa. 2007. "Challenger Entry and Voter Learning." American Political Science Review 101:303-320. 
Groseclose, Tim and James Snyder. 1996. "Buying Supermajorities." American Political Science Review 90:303-315.

Grosser, Jens and Arthur Schram. 2006. "Neighborhood information exchange and voter participation." American Political Science Review 100(2):235-248.

Grosser, Jens and Arthur Schram. 2010. "Public Opinion Polls, Voter Turnout, and Welfare: An Experimental Study." American Journal of Political Science 54(3):700-717.

Güth, Werner, M. Vittoria Levati, Matthias Sutter and Eline Van Der Heijden. 2007. "Leading by example with and without exclusion power in voluntary contribution experiments." Journal of Public Economics 91(5-6):1023-1042.

Hamman, John R., Roberto Weber and Jonathan Woon. 2011. "An Experimental Investigation of Electoral Delegation and the Provision of Public Goods." American Journal of Political Science 55(4):738-752.

Hao, Li and Daniel Houser. 2010. "Honest Lies." GMA Working Paper in Economics No. 11-16.

Headlam, James Wycliffe. 1933. Election by Lot at Athens. Cambridge: Cambridge University Press.

Hermalin, Benjamin E. 1998. "Toward an Economic Theory of Leadership: Leading by Example." American Economic Review 88(5):1188-1206.

Houser, Daniel and Erte Xiao. 2011. "Classification of Natural Language Messages Using A Coordination Game." Experimental Economics 14(1):1-14.

Kartik, Navin and R. Preston McAfee. 2007. "Signaling Character in Electoral Competition." American Economic Review 97(3):852-870.

Key, V. O. 1966. The Responsible Electorate Rationality in Presidential Voting 1936-1960. Belknap Press of Harvard University Press.

Kube, Sebastian and Clemens Puppe. 2009. “(When and How) Do Voters Try to Manipulate? Experimental Evidence from Borda Elections." Public Choice 139(1):39-52.

Lockard, Alan A. 2003. Sortition. In The Encyclopedia of Public Choice, ed. Charles K. Rowley and Friedrich Schneider. Springer US pp. 857-860. 
Lundquist, Tobias, Tore Ellingsen, Erik Gribbe and Magnus Johannesson. 2009. "The Aversion to Lying." Journal of Economic Behavior and Organization 70:81-92.

Manin, Bernard, Adam Przeworski and Susan C. Stokes. 1999. Elections and Representation. In Democracy, Accountability, and Representation, ed. Adam Manin, Bernard Przeworski and Susan Stokes. Cambridge: Cambridge University Press.

Maskin, Eric and Jean Tirole. 2004. "The Politician and the Judge: Accountability in Government." American Economic Review 94(4):1034-1054.

Mazar, Nina, On Amir and Dan Ariely. 2008. "The Dishonesty of Honest People: A Theory of Self-Concept Maintenance." Journal of Marketing Research 45(6):633-644.

Morton, Rebecca and Kenneth Williams. 2010. From Nature to the Lab: Experimental Political Science and the Study of Causality. Cambridge: Cambridge University Press.

Mueller, Dennis C., Robert D. Tollison and D. Willett Thomas. 1972. "Representative Democracy via Random Selection." Public Choice 12(1):57-68.

Mulgan, Richard G. 1984. "Lot as a democratic device of selection." Review of Politics 46(4):539-560.

Olken, Benjamin A. 2010. "Direct Democracy and Local Public Goods: Evidence from a Field Experiment in Indonesia." American Political Science Review 104(2):243-267.

Pétry, François und Collette, Benoît. 2009. "Measuring How Political Parties Keep Their Promises: A Positive Perspective from Political Science." Studies in Public Choice 15(2):6580.

Ringquist, Evan J. and Carl Dasse. 2004. "Lies, Damned Lies, and Campaign Promises." Social Science Quarterly 85(2):400-419.

Rothenberg, Lawrence S. and Mitchell S. Sanders. 2000. "Severing the Electoral Connection: Shirking in the Contemporary Congress." American Journal of Political Science 44(2):316325. 
Schwarz, Daniel, Lisa Schädel and Andreas Ladner. 2010. "Pre-Election Positions and Voting Behaviour in Parliament: Consistency among Swiss MPs." Swiss Political Science Review 16(3):533-564.

Selten, Reinhard. 1967. Die Strategiemethode zur Erforschung des Eingeschränkt Rationalen Verhaltens im Rahmen eines Oligopolexperiments. In Beiträge zur Experimentellen Wirtschaftsforschung, ed. H. Sauermann. Mohr Siebeck pp. 136-68.

Shalvi, Shaul, Jason Dana, Michel JJ Handgraaf and Carsten DeDreu. 2011. "Justified ethicality: Observing desired counterfactuals modifies ethical perceptions and behavior." Organizational Behavior and Human Decision Processes 115:181-190.

Stratmann, T. 2005. "Some Talk: Money in Politics. A (Partial) Review of the Literature." Public Choice 124(1):135-156.

Sulkin, Thomas. 2009. "Campaign Appeals and Legislative Action." Journal of Politics 71(3):1093-1108.

Sulkin, Tracy and Nathaniel Swigger. 2008. "Is There Truth in Advertising? Campaign Ad Images as Signals about Legislative Behavior." The Journal of Politics 70(1):232-244.

Thomson, Robert. 2011. "Citizens evaluations of the fulfillment of election pledges: Evidence from Ireland." Journal of Politics 73(1):187-201.

Tridimas, George. 2011. "Constitutional choice in ancient Athens: the rationality of selection to office by lot." Constitutional Political Economy 23(1):1-21.

Woon, Jonathan. 2012. "Democratic Accountability and Retrospective Voting: A Laboratory Experiment." American Journal of Political Science 56(4):913-930. 